\title{
Benefit Sharing: An Incentive Mechanism for Social Control of Government Expenditure
}

\begin{abstract}
The purpose of this paper is to study the incentives individual members of society face to contribute to a nation's efforts in controlling corruption. A Principal-Agent model is constructed, leading to the following results. First, individual agents do have an interest in devoting a portion of their resources to the nation's control effort. However, the opportunity cost of the effort and a free rider problem reduce the spontaneous provision of individual support to corruption control. Second, to cope with those incentives, a new welfare improving mechanism is proposed, which aligns individual incentives with those of society at no extra cost to the government.
\end{abstract}

Key words: Public finance, social control, governmental control, contract theory, incentives.

JEL Classification codes: H50, H61, D72

\section{Introduction}

The efficient use of public resources is one of the fundamental factors underlying the distinct development paths forged by nations that were initially at a comparable stage of technological development. To be sure, investments in unfinished projects, waste, and the diversion and mismanagement of public resources have a devastating effect not only on a country's public accounts but also on its GDP growth rate. ${ }^{1}$ As an illustration, a recent study (Bugarin and Ellery Jr., 2003) estimates that Brazil wasted approximately 20\% of its gross capital accumulation in the last five decades of the $20^{\text {th }}$ century. Another recent study (Cândido Jr., 2001) concludes that public expenditures are $40 \%$ less productive than private expenditures in that country.

The high social cost associated with this waste has driven Brazilian society to assume a far more active role in controlling public resources and in demanding punishment of those individuals involved in corruption and the diversion of resources. The impeachment of former President Fernando Collor de Mello, which was only made possible by the significant pressure exerted by Brazilian society, represented a milestone in the effort to raise social awareness. Since that time, there have been other examples that demonstrate Brazilians' growing concern with the appropriate use of public resources, including the manhunt for the

\footnotetext{
${ }^{1}$ There is no theoretical unanimity about the effects of corruption on economic development. One trend of the literature highlights the inefficiency-reduction role of corruption as it allows for a Coasian negotiation between the bureaucrat who owns the property rights of public resources and private agents that can benefit from those resources. In a society dominated by a rigid bureaucracy such negotiation may lead to a second best instead of a third best allocation. In Huntington (1968)'s words: "In terms of economic growth, the only thing worse than a society with a rigid, over-centralized, dishonest bureaucracy is one with a rigid, over-centralized, honest bureaucracy". A second trend of the literature notices the symbiotic relationship that may arise between corruption and the bureaucratic structure and concludes that instead of reducing the inefficiency of a rigid bureaucracy, it may in fact induce such rigidity, so that the bureaucrat could benefit of the resulting negotiation process. In that case corruption reduces economic growth by keeping an inefficient bureaucracy. Clearly, the authors of this article agree with this last analysis of the effects of corruption. For an excellent review of that literature see Bardham (1997).
} 
fugitive Paulo César Farias, the anões do orçamento (seven dwarfs budget) financial scandal, the arrest and imprisonment of Judge Nicolau dos Santos Neto, the impeachment of the mayor of São Paulo, Celso Pitta, and more recently, the dissolution of the Superintendence for Northeast Development (Superintendência de Desenvolvimento do Nordeste - Sudene) and of the Superintendence for Amazonian Development (Superintendencia de Desenvolvimento da Amazônia - Sudam), both of which had been transformed into extra-official channels for using public resources for private ends.

Civil society's participation in detecting and monitoring the diversion of public resources is of fundamental importance to the country. First, because it represents a form of civic action that fosters a spirit of national unity centered on the common good. Second, because it carries the potential of frightening corrupt individuals, who face the risk of punishment, and, in this way, deters them from engaging in illicit activities.

Social involvement by average citizens, however, requires dedication and resources, and, moreover, it also competes with their everyday activities such as work and leisure. Given the cost of devoting oneself to social control, citizens have a natural tendency to delegate the responsibility for controlling the Public Administration to the government. Therefore, in the current context, it may be the case that the Federal Government is not taking advantage of the efforts civil society might well be willing to invest in controlling the public administration, were it not for the high cost of this activity.

The purpose of this article is to study the incentives society faces with respect to its participation in the control of public expenditures, and to determine how this participation can be promoted. The second section sets forth the basic ideas of the proposed model. As a benchmark for future comparisons, section 3 develops and solves the optimization problem of an agent who is unaware of his potential for participating in the collective control effort. The following section determines the optimal choice for an agent when he recognizes his role in the control process, although here he receives no government encouragement to become involved. This case highlights the fact that there are limited incentives for civil society to exercise a significant role, to the extent that a natural tendency exists for society to delegate all of the responsibility for control to the government bodies. Recognizing the reduced stimulus for spontaneous social involvement, section 5 analyzes an alternative mechanism that induces civil society to invest its own resources in control without resulting in any additional cost to the State. Section 6 compares that mechanism with others that are actually in use or have been proposed in order to avert behavior that will be harmful to society. Finally, section 7 concludes the study.

\section{Basic Ideas of the Model}

All citizens make use of the public goods and services provided by the State and, as a result, expect the State to use its resources in an efficient and competent manner in order to provide, within the established budgetary constraints, the largest possible volume of goods and services. However, considering the problem of incentives associated with the Public Administration, there occurs large-scale waste of resources, squandered through fraud, overcharging, corruption, and unfinished projects.

Citizens are aware of that waste, feel victimized by it, and have a natural inclination to participate in the control of the Public Administration, denouncing the irregularities they uncover. However, for this contribution to be truly effective, it is essential that these agents devote time and effort to the control process. On the other hand, there are costs to the agents 
for devoting time and effort to safeguarding the public assets, given that they could use the same resources to obtain a higher private return whether by working more or making better use of their leisure time. This phenomenon is known as the "opportunity cost" of control, which requires giving up individual return in order to control wasting public goods.

Thus, an impasse emerges: if the expected social return for the time devoted to control is very low in comparison to the private return that the agent obtains when he devotes himself to his work or leisure activities, his preference will be to transfer all the responsibility for the control of the Public Administration to the government.

Moreover, there is a free rider problem in which an agent who expects that his colleague will devote time and effort to control ends up relying on the other individual without contributing to the general control effort. However, if everyone thinks along those same lines, nobody contributes to the control process. This is a quite common phenomenon in the economics of the public sector, which explains why the voluntary provision of public goods tends to generate a quantity of goods that is much lower than the socially optimal one.

Both of the problems enumerated above, the opportunity cost of control and the free rider problem, drive civil society to distance itself from the control effort, leaving the responsibility for the control of the public administration exclusively in the hands of the formal control institutions. To resolve this problem and actually be able to count on society's participation in the control effort, incentive mechanisms must be created that, in some way, compensate the civil organizations for their efforts.

A possible mechanism proposed in this article consists in awarding financial compensation to institutions that prove to be instrumental in the recovery of diverted public resources. In this case, a portion of the recovered resources would be used for compensation, resulting in no cost to the government. It is important to stress that this does not involve the injudicious distribution of scarce public resources, which would be highly inappropriate, particularly given the current context in which the government has endeavored to remain within tight and responsible budgetary constraints. To the contrary, the idea is to create more latitude within the existing budgetary constraints by introducing a mechanism that would allow for the recovery of those resources that would otherwise be irrevocably lost. The compensation awarded to those institutions that made possible the recovery of those resources would be derived in whole, and exclusively, from the recovered amount. ${ }^{2}$ Note furthermore that the reward to the instrumental agent could be made in kind but also as tax credits, for example, or other mechanisms that would not necessarily imply direct payment to the agent but would have an equivalent incentive effect. ${ }^{3}$

\section{The Basic Model and the Representative Agent's Decision Without Social Involvement}

\section{The Government}

The government has at its disposal a budget in the amount of $B$ monetary units that is to be used to provide public goods and services to society. However, public administrators may divert parts of budget $B$ using several mechanisms such as overcharging, ghost contracts, illicit transfers, etc. Let $\delta$ be a percentage of the total budget that is diverted. Thus, only the

\footnotetext{
${ }^{2}$ In this study, the concept "recovered amount" is broad, encompassing resources that are detected even before becoming effectively diverted.

${ }^{3}$ The authors are grateful to Mirta Bugarin for this insight.
} 
amount $(1-\delta) B$ is actually converted into public goods and services that generate a return to society. The value $\delta B$ corresponds to the amount of the public budget that is lost.

\section{The Public Control Institutions}

The role of the public control institutions is to detect ${ }^{4}$ the diversion $\delta B$. However, the control process does not always allow for the identification of the diverted resources in time to recover the lost amount. This model estimates that the official bodies are able to recover the diverted amount with a probability $\pi_{0} \in[0,1]$. The probability $\pi_{0}$ is an exogenous parameter of the model and, to a certain degree, represents the level of development of the national control system: the larger $\pi_{0}$ is, the more efficient the control bodies are, insofar as they will be able to provide for the recovery of the diverted resources with greater frequency.

\section{Society}

Society is modeled by a representative agent, who derives satisfaction from three basic activities: the consumption of private goods (clothing, food, semidurable and durable goods, etc.), leisure (sports, the arts, performances, rest, etc.), and the consumption of the goods and services provided by the State (healthcare, education, social security, national security, law enforcement, etc.). In the pages that follow, public goods are referred to generically as the entire range of goods and services provided by the State, even though from the standpoint of economic theory this designation is not wholly accurate. ${ }^{5}$

Thus, one can characterize the agent's utility as a function $U(c, l, b)$, in which $c$ corresponds to private consumption, $l$ corresponds to leisure time, and $b$ corresponds to the consumption of public goods. This model assume $b=(1-\delta) B / n$, in which $n$ is the total population. Hence, the consumption of public goods for a representative agent is measured in terms of per-capita consumption of the effectively implemented budget.

The agent is endowed with a unit of time and must decide how to allocate it among three basic activities: work, leisure, and control. Work provides income that is used to purchase the agent's private consumption. Leisure provides no income; however, the time devoted to that activity generates satisfaction for the agent. Finally, the time devoted to control can contribute to the recovery of the diverted resources, so that the agent receives a larger offering of the public goods provided by the State. The agent may or may not recognize the strategic opportunity of contributing to the nation's control effort. This first basic model assumes that the agent does not recognize that opportunity and ascribes all the responsibility for the control of the public administration to the official institutions. In the next sections, that hypothesis will be relaxed.

\footnotetext{
${ }^{4}$ To be sure, the duties of the official control bodies are far more complex, ranging from the prevention of diversions, whenever possible, to the detection and recovery of the diverted resources. This model focuses on the task of detecting the diversion of resources; however, section 8 shows that an additional function of the proposed model is a long-term reduction in the diversion of resources, meaning that it has a preventive effect.

${ }^{5}$ In economic theory, a public good is any good having two basic characteristics, non-exclusion (the costs to exclude an agent from consuming that good are extremely elevated) and non-rivalry (the consumption of that good by an agent does not affect its consumption by other agents), regardless of who is responsible for providing the good. Thus, national defense is a typical example of a public good while education is a publicly provided private good. Conversely, television (but not cable TV) approaches the definition of a public good that is privately provided.
} 


\section{The Agent Maximization Problem}

The utility function for the agent is presented more precisely below.

$$
U(c, l, b)=\alpha u(c)+\beta v(l)+\gamma\left[\pi_{0} w(b)+\left(1-\pi_{0}\right) w((1-\delta) b)\right]
$$

Therefore, it is assumed that agent's utility is additively separable in private consumption, leisure, and the consumption of public goods. The function $u$ represents the specific utility associated with the consumption of private goods $(c)$; the function $v$ computes the satisfaction associated with leisure $(l)$, and the function $w$ expresses the utility derived from the (individual) consumption public goods. Note that the consumption of public goods is a random variable that takes the value $b$ with a probability $\pi_{0}$ (when the diverted resources are recovered), and takes the value $(1-\delta) b$ with a probability $1-\pi_{0}$ (when those resources are not recovered). It is for that reason that the expected value of the satisfaction derived from the consumption of public goods is considered in the utility equation. The present model assumes that the functions $u$ and $v$ and $w$ are strictly increasing, concave, and differentiable, ${ }^{6}$ and that in addition, $u$ and $v$ are strictly concave; thus, the greater the consumption of private goods, leisure time, and the consumption of public goods, the greater the agent's satisfaction; however, the added satisfaction derived from each additional unit of private consumption or leisure decreases, to the extent that the agent already benefits from a large quantity of that consumption or amount of leisure time.

Finally, the positive parameters $\alpha, \beta$, and $\gamma$ (where $\alpha+\beta+\gamma=1$ ) represent the relative weight the satisfaction derived from each of the different activities has in the agent's utility function. Thus, if $\alpha$ is significantly large in comparison to the other parameters, the agent will give more value to the consumption of private goods, while attaching relatively less value to leisure and the consumption of public goods. Similarly, if $\gamma$ is significantly large, the agent will ascribe more value to the consumption of goods and services provided by the State and, as a consequence, could potentially concern himself more with the losses resulting from the unrecovered diverted resources.

Once the agent no longer believes that he can contribute to the government's control effort, his decisions on how to allocate his time will be reduced to choosing how much time to devote to work and how much to leisure. Thus, the agent's maximization problem can be written as follows.

$$
\left\{\begin{array}{c}
\max _{h, l} \alpha u(c)+\beta v(l)+\gamma\left[\pi_{0} w(b)+\left(1-\pi_{0}\right) w((1-\delta) b)\right] \\
\text { s.t. } \quad \begin{array}{c}
h+l \leq 1 \\
c \leq s h
\end{array}
\end{array}\right.
$$

Restriction (1) in the maximization problem states that the agent in endowed with one unit of time (which can be considered as the total number of available hours) that can be allocated among work and leisure activities. The parameter $s$ in restriction (2) is the wage rate, so that if the agent devotes $h$ units of time to work, he will warrant a total wage $s h$ that may then be applied towards his private consumption.

\footnotetext{
${ }^{6}$ Because they are concave, the functions are differentiable except on a set of zero Lebesgue measure, so that the hypothesis is not restrictive.
} 


\section{The Agent's Optimal Choice}

Given that the functions $u$ and $v$ are strictly increasing, the restrictions (1) and (2) are binding. Therefore, one can replace $l$ with $1-h$ and $c$ with $s h$, thereby converting the original problem into a concave program in a single variable. The first-order conditions yield the following solution.

$$
s \alpha u^{\prime}(s h)=\beta v^{\prime}(1-h) \quad \text { and } \quad l=1-h
$$

The solution to the first equation corresponds to the optimal value $h$, which generates the optimal value $l$ for the second equation. In order to present a closed-form expression for the problem's solution, assume that the utilities $u$ and $v$ take the logarithmic form common in economic theory: $u(c)=\log (c)$ and $v(l)=\log (l)$. Therefore, the optimal allocation of time by the agent is given by:

$$
h=\frac{\alpha}{\alpha+\beta} \quad \text { and } \quad l=\frac{\beta}{\alpha+\beta}
$$

Therefore, the greater the satisfaction generated by private consumption vis-à-vis leisure, the more time the agent will devote to work. By the same token, the greater the relative satisfaction derived from leisure activities, the more time that will be devoted to those activities.

\section{The Agent's Decision with Social Involvement but Without Incentives}

\section{Social Involvement}

The model presented in the previous section assumes that the representative agent delegates exclusive responsibility for controlling the public administration to the public institutions. However, the diverted public resources reduce the agent's utility by reducing the per-capita value of $b$ to $(1-\delta) b$. Nonetheless, if the agent contributes to the effort to increase the probability of recovery of the diverted resources, he will increase his own utility.

This section assumes that the agent can affect the probability of recovery of the diverted resources if he invests a portion of his time in control. More specifically, let $t$ be the time the agent devotes to control. The agent, then, will be instrumental in bringing to light the diversion and recovering the public resources with a probability $\pi(t) \in[0,1]$, where $\pi$ is now a strictly increasing function of $t$ : the more time the agent devotes to control, the greater the probability that he will be instrumental in recovering the diverted public resources.

Thus, if time $t$ is invested in control, the total probability of recovering the diverted resources is $\pi_{0}+\pi(t)$, where the first term corresponds to the efforts of the formal control institutions and the second term corresponds to the agent's efforts. It is important to stress that there are certain limits regarding the functional form of the function $\pi$, which increases in $t$ but also depends on the exogenous probability $\pi_{0}$, since a highly efficient formal control system (a very high $\pi_{0}$ ) reduces the chances that society will become instrumental in the recovery of the resources. The present model postulates, when necessary, that $\pi(t)=k \frac{t}{\pi_{0}}$, where $k<\pi_{0}\left(1-\pi_{0}\right)$ is a constant that measures the agent's competence in uncovering illicit diversions: the greater that $k$ is, the more "productive" the agent will be, insofar as there will be a greater probability of recovering the diverted resources. On the other hand, as discussed 
above, the larger $\pi_{0}$, the lower the probability the agent will be instrumental. Note that because of the restriction imposed on parameter $k$, the society can never have total certainty that the diverted resources will be recovered, even if the agent devotes all of his time to control: $\pi_{0}+\pi(1)<1$.

\section{The New Problem of the Agent}

When the agent recognizes the strategic opportunity of social involvement, the problem becomes the allocation of time among three activities: work, leisure, and social control. The new formal problem is presented below.

$$
\left\{\begin{array}{c}
\max _{h, l, t} \alpha u(c)+\beta v(l)+\gamma\left[\left(\pi_{0}+\pi(t)\right) w(b)+\left(1-\left(\pi_{0}+\pi(t)\right)\right) w((1-\delta) b)\right] \\
\text { s.t. } \quad \begin{array}{l}
h+l+t \leq 1 \\
c \leq s h
\end{array}
\end{array}\right.
$$

The restrictions of this problem are the same as in the previous problem, although care must be taken to include the time $t$ expended on control in equation (4).

Once again, on the basis of the monotonicity properties of the functions $u$, $v$, and now $\pi$, the restrictions will be binding. However, as opposed to the previous problem, it is not possible to ensure the existence of an interior solution: $0<h, l, t<1$, which requires the analysis of two separate cases.

\section{The Agent's Optimal Choice with an Interior Solution: Spontaneous Provision of Social Control}

Suppose, in the first instance, that an interior solution exists. In this case, the firstorder conditions applied to the new problem result in the equations below, in which $W(b)=w(b)-w((1-\delta) b)$.

$$
\left\{\begin{array}{l}
t=1-h-l \\
s \alpha u^{\prime}(s h)=\gamma \pi^{\prime}(1-h-l) W(b) \\
\beta v^{\prime}(l)=\gamma \pi^{\prime}(1-h-l) W(b)
\end{array}\right.
$$

Note that it follows from equations (7) and (8) that $s \alpha u^{\prime}(s h)=\beta v^{\prime}(l)$, which corresponds to the same expression as in the previous solution $((1))$, with the difference now that the restriction $h+l=1$ is no longer valid.

Back to the expressions $u(c)=\log (c), v(l)=\log (l)$, and $\pi(t)=k \frac{t}{\pi_{0}}$ for the functions $u, v$, and $\pi$ respectively, conditions (6), (7), and (8) produce the following solution to the problem:

$$
h=\frac{\alpha \pi_{0}}{\gamma k W(b)}, \quad l=\frac{\beta \pi_{0}}{\gamma k W(b)}, \quad t=1-\frac{(\alpha+\beta) \pi_{0}}{\gamma k W(b)}
$$

Note that in this solution the agent decides to devote a portion of his time $(t)$ to social control, not out of altruism or patriotism, but simply to guarantee the improved provision of public goods for himself. Thus, the agent's interest in social control is well founded from the standpoint of his personal incentives, without there being a need to postulate any artificial 
hypotheses with respect to deeper philosophical motivations such as love of country, ethical considerations in the handling of public resources, etc. Nor is there any direct financial incentive offered by the government to justify that behavior. For that reason, one can conclude that the spontaneous provision of social control occurs in this context.

\section{Comparative Statistics}

The solution above is fundamentally dependent on the parameters of the model. That dependence is discussed now.

(i) The greater the efficiency of the official control bodies $\left(\pi_{0}\right)$, the less stimulus society will have to invest its time in social control. Hence, the model suggests that society's participation in the control efforts will decrease as the formal institutions become more effective.

(ii) The greater the civil agent's capability, which is measured by the probability of success in bringing to light the illicit diversions $(k)$, the greater his incentive to participate in social control. Therefore, if $k$ is interpreted as a characteristic of each citizen or each civil organization, one can expect that in the medium term only the most competent organizations will participate in the social-control process. This involves the phenomenon of self-selection, which stipulates that society itself is able to achieve an equilibrium that capitalizes on the comparative advantages of the agents, such that each agent devotes more time to the activity that is most profitable to him.

(iii) The more importance the agent attaches to the public goods $(\gamma)$, the more time he will invest in social control. At the same time, the greater the importance he gives to private consumption or leisure $(\alpha, \beta)$, the smaller the social investment. Thus, we can expect more spontaneous social control in those societies in which the goods and services provided by the State are more important to the citizens.

\section{Is the Provision of Spontaneous Social Control Feasible?}

In order for expressions (9) truly correspond to an interior solution to the problem, it is necessary that $t=1-\frac{\pi_{0}(\alpha+\beta)}{\gamma k W(b)}>0$, or that:

$$
\pi_{0}(\alpha+\beta)<\gamma k W(b)
$$

Note that $W(b)=w(b)-w((1-\delta) b)$ corresponds to the gain obtained by the agent from the recovery of the diverted sum $\delta B$. Given that $b=B / n$, the expression (10) can be rewritten in the following manner.

$$
\pi_{0}(\alpha+\beta)<\gamma k W\left(\frac{B}{n}\right)
$$

When considering that the parameters $\alpha$ and $\beta$ are fixed, the left hand side of (11) is a given positive number. The right hand side of the expression, however, depends on the number of citizens, $n$. As $n$ increases, the term on the right decreases (converging to zero), so that condition (11) is not satisfied. Thus, one can expect that as a society's population grows, ceteris paribus, the value of $t$ in the solution will become progressively smaller, until it 
reaches zero. In this case, the agent will decide not to devote any of his time to social control. This corresponds to a corner solution for the agent's maximization problem $P_{2}$.

On the other hand, if budget $B$ also increases with $n$, then spontaneous provision is practicable. Therefore, one can conclude that countries with small populations or rich countries - even those with large populations - have a greater propensity for spontaneous social control. Unfortunately, Brazil does not appear to fit into either of these categories.

Note, further, that if one were to extrapolate a larger number of private agents for the basic model, a free rider problem would emerge. In the context of this analysis, the free rider problem can be described as follows: if there are several agents, one of them will make use of the benefits (the recovery of diverted resources) deriving from the efforts of the others (the time invested in social control) without, however, having to devote any of his time to that activity; in other words, an agent can free ride on the effort of the others. Consequently, if an agent expects that others will devote themselves to social control, he will choose $t=0$. However, if all agents act in this way in anticipation of benefiting from the efforts of the others, none will invest in social control. ${ }^{7}$

In conclusion, in spite of the fact that spontaneous social control is a feasible choice from a theoretical standpoint, matters regarding the size of the budget relative to the total population, as well as the free-rider problem, suggest that in a country like Brazil society will tend to delegate all of the responsibility for government control to the official bodies. The next section presents an alternative mechanism, the basic purpose of which is to stimulate social control by means of an adequate incentives system, without imposing additional costs on the government.

\section{A Mechanism for Stimulating Civil Society's Participation in Social Control}

\section{The Model with Incentives}

This section considers the case where the agent has no interest in investing a portion of his time in spontaneous social control. In other words, the solution to problem $P_{2}$ is not interior, thereby requiring that $t=0$. The government recognizes the incentive problem and, realizing that it involves a typical principal-agent situation, takes the role of a principal to construct a mechanism that motivates the agent to devote himself to social control. The mechanism works in the following manner: if the agent is instrumental in recovering the diverted public resources $\delta B$, then a percentage $\lambda$ of the resources will immediately revert to the agent himself, while the remaining percentage $(1-\lambda)$ is returned to the treasury.

Therefore, this entails a risk-sharing partnership between the principal and the agent, insofar as the process of social control involves a cost to the agent (the opportunity cost of devoting his time to this activity) as well as risk: the possibility of failure (the agent not being able to detect the diversion, the probability of which is $(1-\pi))$. To stimulate the agent's participation, the government offers him a portion of the return should he succeed. Mechanisms of this nature are widely used both in theoretical models - and comprising the essence of the principal-agent model - and in practical situations. One of the more common and long-standing examples of this principle can be found in the contracts between farmers

\footnotetext{
${ }^{7}$ This involves a phenomenon commonly witnessed in situations related to the voluntary provision of public goods, which results in the inadequate provision of those goods. In the current context, social control can be seen as a public good, given that its return reverts entirely to the benefit of society as a whole.
} 
and landowners, in which the landowner (the principal) provides the land while the farmer (the agent) shares the return of his labor with the landowner: the harvest. ${ }^{8}$

\section{The New Agent Problem}

Given this new mechanism, the agent problem can be rewritten as follows.

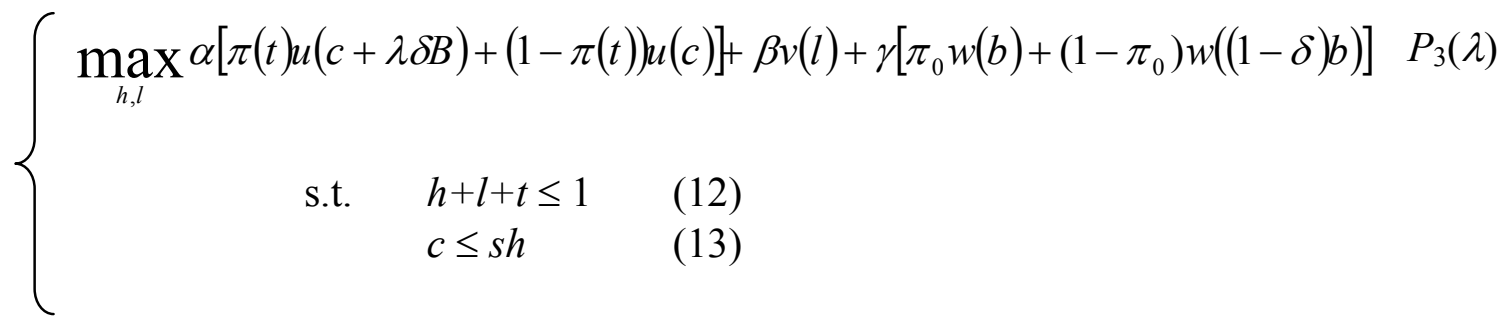

In the expression above, the effect of the recovery initiated by the agent on the provision of the public goods was ignored, specifically the term $(1-\lambda) \delta \frac{B}{n}$ which should be added to the term $(1-\delta) b$ with a probability $\pi(t)$. This simplified form stems from the fact that this effect can, as discussed earlier, supposedly be discarded. Naturally, the inclusion of this effect would serve only to reinforce the incentive for social control set out in this section.

The term $c+\lambda \delta B$ corresponds to the increase in the consumption the agent will merit if he is instrumental in the recovery of the diverted resources, the probability of which is $\pi(t)$. The solution $t(\lambda)$ for this new problem, which depends wholly on the parameter $\lambda$, is analyzed below.

\section{Analysis of the Solution}

The agent's objective-function can be rewritten as:

$$
\alpha u(c)+\beta v(l)+\alpha \pi(t)[u(c+\lambda \delta B)-u(c)]+\gamma\left[\pi_{0} w(b)+\left(1-\pi_{0}\right) w((1-\delta) b)\right]
$$

In comparison to the objective function of problem $P_{1}$, the appearance of the following extra term can be verified: $\alpha \pi(t)[u(c+\lambda \delta B)-u(c)]$. In order to analyze the effect of this term on the agent's decision, the expression is broken down into two parts: $\alpha \pi(t)$ and $u(c+\lambda \delta B)-u(c)$.

Because the utility function $u$ is strictly increasing, the expression $u(c+\lambda \delta B)-u(c)$ is positive. In addition, since the parameter $B$ corresponds to the total amount of the public budget, the term $\lambda \delta B$ is potentially very large if compared to the agent's income $c$. Thus, the net gains in the utility of the agent who receives financial compensation, $u(c+\lambda \delta B)-u(c)$, is potentially high and will be even more substantial as the parameters $\delta$ and $\lambda$ become greater.

However, to make use of the expected gain in utility it is necessary that $\pi(t)>0$, or, in other words, that $t>0$, i.e., that the agent devote some of his time to social control.

Comparing to the situation in which the agent invests nothing in social control, one can conclude from the continuity of the utility functions $u$ and $v$ that a small reduction in $h$ or in $l$ (which makes $t=1-h-l$ positive) will only slightly alter the values of $u(c)=u(s h)$ and $v(l)$.

\footnotetext{
${ }^{8}$ Adam Smith (1797) was one of the first researchers to analyze that sharecropping arrangement, a topic that still today inspires a significant quantity of theoretic and empirical research.
} 
However, it will significantly alter the value of $\alpha \pi(t)[u(c+\lambda \delta B)-u(c)]$, which increases from zero $(t=0)$ to a large positive value. Thus, we can conclude on the basis of the continuity of the functions involved that the problem will have an interior solution, that is, $t>0$.

Therefore, the proposed mechanism will stimulate the agent to invest his time in social control. The topic below shows that the proposed mechanism will also be of interest to the government.

\section{The Government Problem}

The proposed model stimulates the representative agent to invest a portion of his time in social control activities. Consequently, the probability of recovering the diverted resources increases from $\pi 0$ to $\pi_{0}+\pi(t)$.

Consider now the government. Given that it main role is to provide public goods, one may define its utility as the total quantity of public resources actually invested in public goods and services. Therefore, it is possible to make a formal comparison of the effect of the new mechanism on the government's welfare.

Start with a situation in which the agents have no incentive to invest in spontaneous social control. In that case $t=0$ and the government's utility is:

$$
U_{0}=(1-\delta) B+\pi_{0} \delta B
$$

The first term in the expression above corresponds to the amount applied to public goods when the diverted resources $\delta B$ are not recovered, while the second sum corresponds to the value that is recovered by the official control institutions, the probability of which is $\pi 0$.

Consider now the government implements the mechanism, wherein $\lambda \in(0,1)$ is the apportionment parameter. Furthermore, let $t(\lambda)$ be the time the agent allocates to social control, given the parameter $\lambda$. The government's utility then becomes:

$$
U_{\lambda}=(1-\delta) B+\left[\pi_{0}+(1-\lambda) \pi(t(\lambda))\right] \delta B
$$

The difference between $U_{\lambda}$ and $U_{0}$, the term $(1-\lambda) \pi(t(\lambda)) \delta B$, corresponds to the increase in the provision of public goods and services originating in the recovery of the diverted resources arising from the agent's efforts; given that the probability of this recovery is $\pi(t(\lambda))$ and that it is subject to the apportionment $\lambda$, one arrives at the expression above.

One can thus establish that the proposed mechanism leads to an increase in the total expected value of public investment, increasing, in this way, the government's utility, provided that $t(\lambda)>0$. Note that the incentive is implemented at no cost to the government, since the payment is made through the use of resources that would not be available had they not been recovered with the agent's participation.

Also note that the gain occurs for any value of $\lambda$, provided that:

(i) The parameter $\lambda$ is sufficiently high to ensure that $t(\lambda)>0$; and

(ii) The parameter $\lambda$ is smaller than 1 , because otherwise all of the recovered resources would be transferred to the private agent.

Moreover, the smaller that $\lambda$ is, the larger the government's return will be. Thus, the government would prefer to choose a very small value for that parameter. On the other hand, if the value were too low, the agent will invest little time in social control, thus reducing the probability $\pi(t(\lambda))$. Consequently, the government problem can be written, using the principal-agent structure, as: 


$$
\left\{\begin{array}{c}
\max _{\lambda}(1-\delta B)+\left[\pi_{0}+(1-\lambda) \pi(t(\lambda))\right] B \\
\text { r.a. } t(\lambda) \in \underset{t}{\arg \max } P_{3}(\lambda)
\end{array}\right.
$$

The formulation presented above expresses the fact that the government will choose the factor $\lambda$ when it knows that, for each value of $\lambda$, the agent will solve his maximization problem $P_{3}(\lambda)$, thereby producing the choice $t(\lambda)$. For example, on the basis of the earlier discussion, if $\lambda=0$ then $t(\lambda)=0$, but if $\lambda>0$ then $t(\lambda)>0$.

Note that, in equilibrium, the government will obtain the highest possible return when choosing the value $\lambda$ that induces an optimal participation of society in the control process.

\section{Other Mechanisms}

In spite of the originality of the proposed mechanism, which requires sharing with civil society the benefits of the recovered resources, the present model belongs to a family of mechanisms that aim at creating the right incentives for revelation and correction of behavior that is damaging to society.

In the case of private firms collusion, a most important mechanism concerns the leniency programs that allow agreements between the government and a company involved in cartel activities with other companies. Leniency legislation started in the USA in 1978 and had its scope greatly extended in 1993. Since then other countries have passed leniency laws such as the European Union in 1996, Korea in 1997, England, Germany, Canada and Brazil in 2000. The leniency agreements have the following basic characteristics. When the government suspects that companies (or even individuals such as company directors) are involved in cartel activities it can sign contracts with one of the firms involved that reduce or even eliminates all applicable fines and other legal charges to the firm that cooperates with the investigation. ${ }^{9}$ The leniency laws have resulted in impressive numbers both in terms of the punishments and in terms of the amounts of the fines. To cite two illustrative examples, the Antitrust Division of the U.S. Department of Justice have collected over 1.1 billion dollars in fines; moreover, the famous case of the vitamin cartel, where Rhöne-Poulenc cooperated with justice signing a leniency agreement, resulted in the incarceration for five months of the President of Hoffman-LaRoche, a swiss resident in addition to a personal fine of 150 thousand dollars. ${ }^{10}$

Therefore, leniency contracts seem to have been an effective that creates incentives for companies involved in cartel activities to come forward and dismantle that illegal activity in exchange for amnesty of its own liability. Note that, in order to avoid abuses the law states that a company shall not be the leader in the organization of the cartel in order to be able to sign a leniency agreement. Moreover, only the first company to come forward is entitled to amnesty under most leniency laws. If one compares the leniency mechanism with the benefit sharing one proposed here one observe that the leniency one demands more from the

\footnotetext{
${ }^{9}$ For the American case see Paul (200) or Letrc Law Library (08/10/1994). For a comparison between the American and the European Community leniency laws, see Feess \& Walzl (2003). For the Brazilian case see Considera et all (2001).

${ }^{10}$ See Paul (2000).
} 
government in the sense that it gives amnesty to a company involved in unlawful activities, whereas the benefit-sharing mechanism only rewards those who were instrumental in recovering diverted public resources.

When it comes to incentives within the public administration, the Revenue System usually have the most sophisticated mechanisms. When an auditor fines a company for tax evasion part of the fine reverts to himself as a mechanism for avoiding collusion between the evader and auditor. ${ }^{11}$ That mechanism brings an additional benefit to the auditor that compensates him for the opportunity cost of his dedicated and uncorrupted work, just as the shared benefit compensates society for the opportunity cost of the time spent in social control.

Finally, a more radical mechanism has been recently proposed in the tax evasion literature. The mechanism tells a company that has corrupted an auditor that she can come forward and its tax evasion will be forgiven. In fact the corrupted auditor shall be liable for that evasion and will be jailed in case he cannot compensate the government for that last revenue. According to the author of the proposal, the mechanism is equivalent to sending to all companies the following letter.

"Dear Evader:

If you did not pay your taxes and were discovered by an auditor, TRY TO CORRUPT HIM BY PAYING HIM A BRIBE, and then come to us, confess your evasion and report the corruption. By doing so you will help us to catch corrupt auditors and in return we will transfer the obligation of your present and past taxes and fines to them. Help us to catch corrupt auditors and we will forgive your evasion. ",12

The short review presented here shows that there exists a rich literature with various mechanisms that are already used in order to induce agents to cooperate with government effort to control damaging behavior to society. Some of those mechanisms go as far as requiring the government to give up fines and other punishments to delinquent companies and individuals in order to achieve their goals.

\section{Conclusion}

The formal study of the proposed mechanism highlights the government's strategic opportunity to induce civil society to engage into the social control process, and, in this way, reduce the diversion of public resources. It is an inexpensive mechanism for the government that does not result in the ex ante disbursement of any resources, since disbursement is restricted to those situations in which diverted resources are recovered.

Clearly, however, the implementation such a mechanism is subject to a series of adjustments given the adverse incentives it can cause. In general, care should be taken each time the government decides to exercise its role as a principal to induce society into adopting a specific pattern of conduct. For purposes of the particular case considered in this study, some of the difficulties that must be resolved to ensure the mechanism's success need to be pointed out.

In the first place, the concept of the agent's "instrumentality" in recovering the resources must be made clear. A mere accusation lacking solid substantiation should not, even if later borne out, be sufficient to guarantee access to the recovered resources. A pre-

\footnotetext{
${ }^{11}$ See, for example, Besley \& MaLaren (1993).

${ }^{12}$ Ordoñez (2002).
} 
established level of minimum requirements with respect to evidence and other legal instruments should be required to avoid an avalanche of baseless accusations. In the second place, law enforcement and the Judicial System must be prepared to impose the applicable penalties and execute the recovery of the diverted resources. It is essential that these institutions have considerable flexibility and act quickly in order to make sure that the share owed to the private agent is transferred to him, so that he feels genuinely stimulated to invest his time in social control. Finally, precautions should be taken to avoid the formation of coalitions between official control and organized civil institutions, whereby the public sector first discovers the diverted resources but proceeds to pass the information on to nongovernmental organizations in order to obtain, via rent seeking, part of the return that the latter entity is slated to receive.

These are complex matters. However, they are typical situations that occur when the government decides to intervene in the social equilibrium. Considering the maturation of Brazilian and other developing societies in the last years as a result of the consolidation of their institutions, the hope is that these problems will be resolved satisfactorily.

Considering the originality of the proposed mechanism, one can only speculate about its long-term effects. However, it seems clear that there will be some specialization of the non-governmental institutions that devote themselves to social control, since experience and the presence of some form of professional structure will have the effect, potentially, of elevating the probability for success (the parameter $k$ in the model) of such an institution. Thus, a great deal of competition can be expected initially, when many organizations will seek to obtain the resources associated with the recovery of diverted resources; however, this initial euphoria should give way to a subsequent stage marked by a balance among more specialized institutions.

Another trend that be can expected is that as the probability that diverted resources will be detected increases - provided it is accompanied by rigorous penalties for those involved - corrupt individuals will feel more threatened and, consequently, the percentage $\delta$ of diverted resources will tend to decrease. But then, the government will be maximizing the volume of resources it applies to public goods and services and, by the same token, the sums shared with non-governmental organizations will reduce: the very fear of being exposed by a society highly involved in social control - in addition to regular government control - will serve as an important factor in inhibiting the diversion of resources (the $\delta$ parameter in the model), further increasing the government's return on the implementation of such a mechanism.

The extension of the model in order to endogenize the decision of how much to deviate and to explore the dynamic effects of the benefit-sharing mechanism is a suggestion for future research.

\section{References}

BARDHAN, Pranab. "Corruption and Development: A Review of Issues". Journal of Economic Literature, 35(3):1320-1346, 1997.

BESLEY, Timothy \& MACLAREN, John. "Taxes and Bribery: The Role of Wage Incentives", Economic Journal, 103(416):119-41, 1993. 
BUGARIN, Mirta, GOMES, Victor \& ELLERY Jr., Roberto. "Long Run Implications of the Brazilian Capital Stock and Income Estimates". Department of Economics Working Paper 278. University of Brasilia, February 14, 2003.

CÂNDIDO Jr., J. O. Os Gastos Públicos no Brasil São Produtivos? (Is Public Expenditure in Brazil Productive?) IPEA working paper 781, 2001.

COASE, Ronald. "The Problem of Social Cost". Journal of Law and Economics, 1:1-44, 1960.

CONSIDERA, Claudio, CORREAA, Paulo e GUANAIS, Frederico. "Building a Leniency and Amnesty Policy: the Brazilian Experience". Global Competition Review, 44-46, June/July 2001 .

DUNN, Delmer D. \& UHR, John. "Accountability and Responsibility in Modern Democratic Governments". Annual Meeting of the American Political Science Association. Washington, D.C., Sept. 2-5, 1993.

FEESS, Eberhard \& WALZL, Markus. "Corporate leniency programs in the EU and the USA”. Working paper. University of Aachen, 2003.

HAGGARD, Stephan. "The Reform of the State in Latin America". Word Bank Meeting on Latin American Development. Rio de Janeiro, June 12-13, 1995.

HUNTINGTON, Samuel P. "Political Order in Changing Societies”. New Haven: Yale Univ. Press, 1968.

LAFFONT, Jean J. "The Economics of Uncertainty and Information". Cambridge: MIT Press, 1989.

LECTRIC LAW JOURNAL. "DOJ Antitrust Leniency Policy for Individuals”. 10/08/1994. http://www.lectlaw.com/files/ant11.htm

NORTH, Douglas C. "Institutions, Institutional Change and Economic Performance". New York: Cambridge University Press, 1990.

OLSON, Mancur. "The Logic of Collective Action. Public Goods and the Theory of Groups". Cambridge: Harvard University Press, 1971.

ORDAÑEZ, Guillermo. "Let the Mouse Hunt the Cat: A Way to Evade Evasion, Corrupting Corruption", Annals of the 2002 Meeting of the Latin American and Caribbean Economic Association. Madrid, 2002.

PAUL, Robert D. "International Cartels in Crosshairs". New York Law Journal, 11/09/2000.

PETREI, Humberto (with PETREI, Romeo E.) "Budget and Control - Reforming the Public Sector in Latin America." Washington, D.C.: Inter-American Development Bank and The Johns Hopkins University Press, 1998.

SMITH, Adam. "The Wealth of Nations". New York: The Modern Library, 1776.

TIROLE, Jean. "The Internal Organization of Government." Oxford Economic Papers, 46:129, 1994. 